\title{
CORRELATION BETWEEN JOB AUTONOMY AND PSYCHOLOGICAL CAPITAL WITH WORK ENGAGEMENT
}

\author{
Alfariza Syahnaz \\ Faculty of Psychology, University of Airlangga, Indonesia \\ E-mail: syahnazalfa@gmail.com
}

\begin{abstract}
Work engagement has been considered as a key indicator of organizational health because it significantly influences employees' performance, job satisfaction, turnover intensity, and organizational success. Based on The JD-R Theory, job resources and personal resources could affect work engagement. The study aims to explain the correlation between job autonomy and psychological capital with work engagement. This study was conducted on employees with a total subject of 106 people. The data collection instruments used in this study are UWES (Utrecht Work Engagement Scale), The Measurement of Work Autonomy, and PCQ (Psychological Capital Questionnaire). Data analysis was performed using statistical techniques of multiple regression and Pearson correlation with the help of IBM SPSS for Mac Version 22.0. The results of this study show: 1) Job autonomy and psychological capital have a correlation with work engagement $(F=38,952 ; p<0,05)$. Job autonomy and psychological capital give 43,1\% $\left(R^{2}=0,431\right)$ effective contribution; 2$)$ Job autonomy has a correlation with work engagement $(r=0,346 ; p<0,05 ;) ; 3)$ psychological capital has a correlation with work engagement $(r=0,656 ; p<0,05)$. The company could empower the employee on considering work methods, schedules, and goal criteria. The company may give reward stimulation. The employee could increase their performance by reaching goal targets and give each other compliments and positive experience.
\end{abstract}

\section{KEY WORDS}

Job autonomy, psychological capital, work engagement.

Bakker et al., (2008) stated the need for research on Positive Organizational Behavior (POB), learning and application of positive human resource-oriented and psychological functions that can be measured, developed, and regulated for performance improvement in the current company (Luthans, 2002 in Bakker \& Demerouti 2008). Work engagement has a relevant influence on the company such as employee performance (Demerouti \& Cropanzano, 2010), the creativity and charisma of the leader (Bakker and Xanthopoulou, 2013), also well being for each individual and work team (Salanova et al., 2003 in Costa, Passos \& Bakker, 2016). Therefore, this study will focus on work engagement as one of the positive organizational behaviors.

Work engagement is a positive, fulfilling, work-related experience that includes three complementary dimensions: an energetic (i.e. vigor), and affective (i.e. dedication) and a cognitive dimension (i.e. absorption) (Schaufeli \& Bakker, 2004). According to The JD-R Model of work engagement, job demands and job resources can predict work engagement (Bakker \& Demerouti, 2008). Job demands refer to those physical, psychological, social, or organizational aspects of the job that require sustained physical and/or psychological (cognitive and emotional) effort or skill and are therefore associated with certain physiological and/or psychological costs. Job resources refer to those physical, psychological, social, or organizational aspects of the job that (a) are either/ or functional in achieving goals, (b) reduce job demands and the associated physiological and psychological costs, and (c) stimulate personal growth, learning, and development (Bakker \& Demerouti, 2007). Job resources refer to social support, performance feedback, and autonomy (Bakker \&Demerouti, 2008).

Further, Xanthopoulou et al., (2007) expanded the JD-R Model by showing that job and personal resources are mutually related and that personal resources can be independent 
predictors of work engagement. Personal resources are aspects of the self that are generally linked to resiliency and refer to individuals' sense of their ability to control and impact upon their environment successfully (Hobfoll et al., 2003 in Bakker \& Leiter, 2010). Halbesleben research (in Bakker \& Leiter, 2010) shows that engagement is very influential with resources, especially those that focus on social support, autonomy and self-efficacy which are aspects of psychological capital. Xanthopoulou et al., (2007) stated that job resources and personal resources could affect work engagement.

On this study, we focused on job autonomy as a job resource and psychological capital as personal resources. Both predicted have a correlation with work engagement. Job autonomy and psychological capital act as intrinsic motivation. Both are followed by a passion for developing and achieving goals, being involved in their growth, and focusing on their goals. Therefore, if employees have high job autonomy and high psychological capital followed by high work engagement as well.

Major Hypothesis: There is a correlation between job autonomy and psychological capital with work engagement.

Employees who have the freedom to do their jobs and manage their schedules will increase their motivation to achieve work goals, so they work with diligence, exert energy on their work, and feel enthusiastic about their work. Several studies have confirmed that autonomy and work engagement are positively correlated (Schaufeli \& Bakker, 2004). De Spiegelare et al., (2014) research on job autonomy and work engagement shows that there is a correlation between job autonomy and work engagement.

Minor Hypothesis 1: There is a correlation between job autonomy with work engagement.

Employees, who have high psychological capital, are more confident to do challenging tasks and make positive attribution of success now or in the future, determine the direction to achieve success goals and can rise again when hit by problems. Based on the JD-R theory, psychological capital as a personal resource is an important and direct factor to predict work engagement. (Hobfoll, 1989, 2001 in Karatepe \& Olugbade, 2009). The results of the S. Paek et. al., (2015) study state that there is a positive correlation between psychological capital and work engagement.

Minor Hypothesis 2: There is a correlation between job autonomy with work engagement.

\section{METHODS OF RESEARCH}

This quantitative research used survey methods. The subjects in this study were 106 employees of PT. Aneka Jasa Grhadika Gresik, East Java, Indonesia. There were three questionnaires used in this data collection. The first questionnaire is UWES (Utrecht Work Engagement Scale) $(\alpha=0,921)$, the second questionnaire is The Measurement of Work Autonomy ( $\alpha=0,831$ ), and the third questionnaire is PCQ (Psychological Capital Questionnaire) ( $\alpha=0,867)$. The sampling technique used convenience sampling techniques. The data analysis technique used multiple regression techniques to and Pearson correlation. Multiple regression techniques used for the purpose to examine major hypothesis. Pearson correlation used for the purpose to examine minor hypothesis.

\section{RESULTS AND DISCUSSION}

Job autonomy and psychological capital are correlated to work engagement ( $F=38,952$; $\mathrm{p}<0,05)$. Employees with high job autonomy and high psychological capital are followed by high levels of work engagement. Employees with low job autonomy and low psychological capital are followed by low levels of work engagement. From the multiple regression analysis obtained $\mathrm{R}^{2}=0,481$. That means job autonomy and psychological capital can affect work engagement up to $48,1 \%$, while the remaining $51,9 \%$ can be affected by other factors outside the research. The results of the study support the hypothesis, which states there is a correlation between job autonomy and psychological capital with work engagement. 
Table 1 - Correlation between Job Autonomy and Psychological Capital with Work Engagement

\begin{tabular}{cccc}
\hline Variable & $\mathrm{F}$ & $\mathrm{p}$ & $\mathrm{R}^{2}$ \\
\hline Job Autonomy - Psychological Capital with Work Engagement & 38,952 & 0,000 & 0,431 \\
\hline
\end{tabular}

Table 2 - Correlation between Job Autonomy with Work Engagement

\begin{tabular}{cccc}
\hline Variable & $r$ & $p$ & \\
\hline Job autonomy with work engagement & 0,346 & 0,000 \\
\hline
\end{tabular}

Job autonomy has a significant correlation with work engagement $(r=0,346 ; p<0,05)$. Employees with high job autonomy also have high work engagement. The results of the study support the hypothesis, which states there is a correlation between job autonomy with work engagement. This result is in line with De Spiegelare et al., (2014) research on job autonomy and work engagement which stated that there is a correlation between job autonomy and work engagement.

Table 3 - Correlation between Psychological Capital with Work Engagement

\begin{tabular}{ccc}
\hline Variable & $r$ & $p$ \\
\hline Psychological Capital with work engagement & 0,656 & 0,000 \\
\hline
\end{tabular}

Psychological capital has a significant correlation with work engagement $(r=0,656$; $p<0,05)$. Employees with high psychological capital can also have high work engagement. The results of the study support the hypothesis 3 , which states there is a correlation between psychological capitals with work engagement. This result also supports the statement of Xanthopoulou et al, (2007) about personal resources that can predict work engagement.

\section{CONCLUSION AND RECOMMENDATIONS}

According to the result of this study, it can be concluded that there is a significant correlation between job autonomy and psychological capital with work engagement. Therefore, the company could empower their employees in terms of determining the method, scheduling, and criteria for achieving work targets. Giving autonomy might adjust to the employee's character.

Employees could improve their ability to work with the success of achieving goals, so the managers or supervisors could give trust to employees in the form of flexibility in determining methods, scheduling, and achievement criteria

Companies can provide stimulation with rewards and recognition for employees who successfully carry out their duties. It can build the employee's self-confidence to do more challenging tasks and make a positive attribution.

Employees may give each other compliments, and appreciate positive experiences, so they can increase their confidence and be more optimistic about their achievements in doing the challenging tasks. It can also increase their work engagement.

\section{REFERENCES}

1. Bakker, A.B., \& Demerouti, E. (2007). The job demands-resources model: state of the art. Journal of Managerial Psychology. 22(3), $309-328$.

2. Bakker, A. B., \& E. Demerouti (2008). Towards a model of work engagement. Career development international, 13(3): 209-223.

3. Bakker, A. B., \& Leiter, M.P. (2010). Work engagement: A handbook of essential theory and research. New York: Psychology Press.

4. Bakker, A.B., Schaufeli, WB., Leiter, MP, \& Taris, TW. (2008). Work Engagement: An emerging concept in occupational health psychology. Work \& Stress. 22(3), 187-200. 
5. Bakker, A.B., \& Xanthopoulou, D. (2013). Creativity and charisma among female leaders: The role of resources and work engagement. The International Journal of Human Resource Management, 24 (14), 2760-2779.

6. Costa, P. L., Passos, A.M., \& Bakker, A.B. (2016). The work engagement grid: predicting engagement from two core dimensions. Journal of Managerial Psychology, 31(4), 774789.

7. De Spiegelaere, S., Gyes, G.V., Witte, D.W., Niesen, W., \& Hootegem, G.V. (2014). On the relation of job insecurity, job autonomy, innovative work behavior and the mediating effect of work engagement. Creativity and Innovation Management, 23(3), 318-330.

8. Demerouti, E., \& Cropanzano, R. (2010). From thought to action: Employee work engagement and job performance. In A. B. Bakker \& M. P. Leiter (Eds.), Work engagement: A handbook of essential theory and research (pp. 147-163). New York: Psychology Press.

9. Karatepe, O.M., \& Olugbade, O.A. (2009). The effects of job and personal resources on hotel employees' work engagement, International Journal of Hospitality Management, 28 (4), 504-512.

10. Paek, S., Schuckert, M., Kim, T.T., \& Lee, G. (2015). Why is hospitality employees' psychological capital important? The effects of psychological capital on work engagement and employee morale. International Journal of Hospitality Management, 50, 9-26.

11. Schaufeli, W.B., \& Bakker, A.B., (2004). Job demands, job resources, and their relationship with burnout and engagement: a multi-sample study. J. Organ.Behav, 25(3), 293-315.

12. Xanthopoulou, D., Bakker, A.B., Demerouti, E. \& Schaufeli, W.B. (2007a), The role of personal resources in the job demands-resources model, International Journal of Stress Management. 14,121-41. 